\section{Primary health care: a necessity in developing countries?}

\author{
Evaezi Okpokoro \\ Institute of Human Virology Nigeria \\ (IHVN), Abuja, Nigeria
}

\begin{abstract}
Resource limited countries continue to be plagued with rising prevalence of malaria, tuberculosis, HIV/AIDS as well as other emerging diseases despite the huge financial support provided by bilateral and multilateral agencies to combat these diseases. While progress may have been made in reducing the global burden caused by these diseases on one hand, there has also been a weakening of the primary health care facility on the other hand which was the hallmark to the Alma Ata declaration of 1978. More attention has been placed on our global health needs while the diverse health needs of every community have been neglected. This fatal neglect at the community level highlights the need for the provision of specialize primary health care (PHC) facilities which should not only be affordable, accessible and available, but be appropriate to the priority health needs of the community, especially at the rural level. Hence specialized PHC facilities will be tailored to meet the most pressing health needs of the communities it covers among other diseases. Consequently, this innovative approach will not only strengthen the primary health care system by improving wellbeing especially at the rural level but will also improve the outcome of vertical program at communities where it is most needed.
\end{abstract}

\section{Introduction}

The right to health is a universal human right which underpins the continuous call for universal health care. This call is ever more so in developing countries where there is limited access to basic health care. As a result, the World Health organization (WHO) advocates primary health care (PHC) as the key towards achieving universal health. However, has PHC channeled us closer towards this aspiration? Or has it been a road-block? This review therefore aims to: i) highlight the relevance of $\mathrm{PHC}$ in achieving universal health; ii) pinpoint the hurdles within the context of developing countries; iii) identify future research areas which would advance the attainment of individual right to health through utilization of primary health care.

\section{Background}

Every nation should be interested in the health of its citizens as the health index of any nation is closely linked with her economical and social growth. Studies have shown that the growing burden of diseases is inversely related to economic growth especially in developing countries. For example, in Zambia, two-thirds of families that lose the head of the household in death to HIV/AIDS experience a staggering $80 \%$ drop in monthly income. ${ }^{1}$ Furthermore, the uneven distribution of social determinants of health such as income, housing, healthy environment, employment as well as the limited accessibility, affordability and availability of essential health services has led to widening health inequities between the high and low socio economic communities. ${ }^{2}$ This shows that achieving universal health is still a tall vision for resource limited countries.

\section{Relevance of primary health care in the attainment of uni- versal health - the Alma Ata declaration}

Universal access to health care for every person within any geographical area has been emphasized in achieving universal health. ${ }^{3}$ On the contrary though, a study in Nova Scotia, Canada where there is universal access to health, identified individual socioeconomic characteristics as a more important determinant of health. However, this study made use of secondary data analysis hence confounders were barely adjusted. ${ }^{4}$ Nonetheless, a WHO conference in 1978 at Alma Ata (former Soviet Republic), declared PHC as a universal tool in achieving universal health by the year $2000 .^{5}$ This declaration focused on the attainment of a level of health that permits all people to lead a socially and economically productive life, ${ }^{6}$ hence, it emphasized the provision of crucial services such as: education on prevailing health issues; promotion of food security with proper nutrition; adequate water supply; maternal and child health care; immunization; prevention and control of locally endemic diseases; appropriate treatment of common disease; and the provision of essential drugs. ${ }^{5}$ Also, some of the specific health for all goals were: $5 \%$ of gross national product should be devoted to health; local health care units to possess at least 20 essential drugs etc. ${ }^{5,7} \mathrm{PHC}$ was therefore be seen as a holistic, sustainable and relatively inexpensive approach in promoting and maintaining population health when compared to specialty and in-patient care ${ }^{8}$
Correspondence: Evaezi Okpokoro, Institute of Human Virology Nigeria, Plot 252, Herbert Macaulay Way, Central Business District, P.O. Box 9396, Garki, Abuja, Nigeria.

Tel: +234 8139444759 (c); +234 8058460765 (c) Fax: 09.234 0554, 2340552.

E-mail: eokpokoro@ihvnigeria.org;

evaezio@yahoo.com

Key words: primary health care, universal health, resource limited countries, developing countries.

Received for publication: 5 May 2011.

Revision received: 15 November 2012.

Accepted for publication: 25 May 2013.

This work is licensed under a Creative Commons Attribution NonCommercial 3.0 License (CC BYNC 3.0).

(C) Copyright E.Okpokoro, 2013

Licensee PAGEPress, Italy

Journal of Public Health in Africa 2013; 4:e17 doi:10.4081/jphia.2013.e17

while at the same time an instrument for socioeconomic development. ${ }^{7}$ For example, a 15-year study (between 1982-83 and 1992-94) conducted by the UK medical research council in Gambia compared the level of infant and child mortality between villages with PHC and without PHC. This study showed a marked drop in infant mortality of $49 \%$ in PHC villages and $41 \%$ in non PHC villages. ${ }^{5}$

In addition, resource limited countries cannot afford universal health insurance as existing in developed countries, hence must maximize the use of well structured PHC facilities in boosting the quality of health of its populace. For example, Japan has a high quality of health despite the unsuccessful implementation of PHC, mainly because a high portion of its populace is covered by health insurance. ${ }^{9}$ Therefore, the adoption of PHC following the declaration of Alma Ata as the official blueprint for the provision of essential health services was invaluable especially for developing countries.

\section{The hurdles and the debate}

Despite these relevance, the adoption of PHC has been sidetracked by the introduction of Selective PHC (SPHC). ${ }^{5}$ This method unlike the broad and idealistic Alma Ata declaration with probably unrealistic timelines, is cost effective, more result oriented, hence the reintroduction of vertical programs. ${ }^{7}$

As a result, the use of vertical program with its top down approach has created a paternal relationship between funding agencies and 
recipient communities which is contrary to the principles of community empowerment, community participation and social justice. This unsustainable approach has therefore weakened the PHC structure within developing countries which was the essence of the declaration of Alma Ata. Hence, the focus within most PHC facilities in developing countries is continually being determined by the availability of donor funds for specific disease burden rather than the health needs of the individual communities. Therefore what will happen when the donor funds get exhausted? How long will the ministries of health in developing countries have to dance to the tune of funding agencies? What will happen when a new deadly disease emerges in communities without a structural and functional PHC? Diseases like malaria and TB will continue to re-emerge until PHC structures are strengthened and functional in the context of developing countries. The millennium development goals though closely related to the essentials services of the Alma Ata are hardly achievable using the vertical approach. Hence, developing countries will continue to lag behind these goals until PHC facilities are empowered using the bottom-top approach.

Furthermore, undergraduate medical training curriculum being used in developing countries has failed to capture these issues in preparation of future PHC professionals rather these to-be professionals perceive PHC training as anti-intellectual, less prestigious and non-scientific. ${ }^{7}$ Consequently, Nigeria is currently experiencing shortage of PHC professionals. As such, the few frontline lay health workers at the PHC facilities are over bombarded with numerous training on global health issues such as HIV/AIDS, malaria and tuberculosis from several donor agencies irrespective of their intellectual abilities to cope with these massive transfers of knowledge.

Furthermore, PHC in developing countries is also being delivered in an unplanned environment, with very hazy integration and coordination of health service delivery especially at the rural level. These PHC facilities have continuously been negatively influenced by both political and economic interest, rather than the health needs of individual communities. ${ }^{10}$ Hence these facilities may not fit the health needs of the community where it serves, thus, utilization may be sub optimal. A study by Mead and Roland ${ }^{11}$ shows that ethnic minority patients when compared to white patients evaluate medical care negatively, which may be because they have different health needs compared to white patients. ${ }^{11}$

\section{Future research areas}

Irrespective of the political and economical barrier to health equity, there is the need for specialized PHC which should fit priority health needs of the communities it serves. PHC should not only be affordable, accessible and available, but be appropriate to the priority needs of the community, irrespective of the availability of vertical programs by donor agencies. Therefore critical areas for future research may include:

- studies which compares the community health needs and the utilization of PHC facilities will provide further insight on the possibility for a health need-fit model as a means of improving the structure and use of PHC which will inevitably improve PHC accessibility and utilization.

- studies which assess the methodology for achieving universal health especially at the PHC level should be the focus of current research rather than political and economic ideologies which has been a major roadblock in achieving the goals of the Alma Ata. ${ }^{5}$

studies which audits the avalanche of funds from donor agencies which comes via implementing partners to developing countries in comparison with the establishment of viable PHC structures which would meet the exacting health needs and socio-cultural challenges of different PHC facilities within each geographical region.

In addition to these, emphasis should be on the recruitment of adequate numbers of PHC workers by the state and local government before donor agencies can have a meaningful impact through the provision of the training and transfer of knowledge to these PHC workers. Relevant PHC training institutes should be established at the State level, while the local government recruits individuals at the village levels for admission unto these institutes. These suggestions would thus enable developing countries meet the new target being proposed by the Pan American Health Organization which is health for all in the $21^{\text {st }}$ century. ${ }^{7}$

\section{Conclusions}

The concept and benefits of PHC is still relevant though sub optimized in achieving universal health in developing countries. The current practice of SPHC though more cost effec- tive has been a road block in achieving sustainable universal health coverage. Therefore it is urgent to contextualize this practice within the framework of the health needs of communities in developing countries. This will not only improve universal health but will strengthen the PHC structure, encourage research based decisions and thus prioritize use of limited resources.

\section{References}

1. Russell S. The economic burden of illness for households in developing countries: a review of studies focusing on malaria, tuberculosis and HIV. Am J Trop Med Hyg 2004;71:147-55.

2. Braveman PA. Monitoring equity in health and healthcare: a conceptual framework. $\mathrm{J}$ Health Pop Nutr 2003;21:181-92.

3. Meades K, Roberts R. Universal health care. Am Heart Hospital J 2007;5:217-22.

4. Veugelers PJ, Yip AM, Kephart G. Proximate and contextual socioeconomic determinants of mortality: multilevel approaches in a setting with universal health care coverage. Am J Epidemiol 2001;154:725-32.

5. Hall JJ, Taylor R. Health for all beyond 2000: the demise of the Alma-Ata declaration and primary health care in developing countries. MJA 2003;178:17-20.

6. Julia AW, Kenneths W. Selective primary health care: an interim strategy for disease control in developing countries. Soc Sci Med 1980;14:145-63.

7. Cueto M. The origins of primary health care and selective primary health care. Am J Public Health 2004;94:1864-74.

8. Guagliardo MF. Spatial accessibility of primary care: concepts, methods and challenges. Int J Health Geogr 2004;3:1-13.

9. Tsuda T, Aoyama H, Frodm J. Primary health care in Japan and the United States. Soc Sci Med 1994;38:489-95.

10. WHO. Priorities for research to take forward the health equity policy agenda. Bull World Health Organ 2005;83:948-53.

11. Mead N, Roland M. Understanding why some ethnic minority patients evaluate medical care more negatively than white patients: a cross sectional analysis of a routine patient survey in English general practices. Br Med J 2009;339:b3450. 